\title{
ACTRIS non-methane hydrocarbon intercomparison experiment in Europe to support WMO-GAW and EMEP observation networks
}

\author{
C. C. Hoerger et al.
}

Correspondence to: C. C. Hoerger (corinne.hoerger@empa.ch) 
In the following the set-up and the measurement results of the PTR-MS are presented.

\section{PTR-MS instrumentation}

The proton transfer reaction mass spectrometer (PTR-MS, Ionicon Analytik GmbH, Austria) is described in detail by Lindinger et al. (1998), de Gouw et al. (2003), Warneke et al. (2003), de Gouw and Warneke (2007) and the used instrument calibration and data processing method by Taipale et al. (2008). In brief, the air samples are directly fed to the PTR-MS (Ionicon Analytik GmbH, Austria, Table 4) without any drying or other pretreatments. The volatile organic compounds (VOCs) are ionized in a proton transfer reaction with hydronium ions $\left(\mathrm{H}_{3} \mathrm{O}^{+}\right)$. The PTR-MS consists of three parts: a discharge ion source to produce the primary ions, a drift-tube reactor, and a quadrupole mass spectrometer for detecting primary and product ions. The $\mathrm{H}_{3} \mathrm{O}^{+}$ions are produced in a hollow discharge cathode from pure water vapor and guided to the reaction chamber through a small orifice. The air sample is fed continuously through the drift tube, where the VOCs of the air sample collide with the $\mathrm{H}_{3} \mathrm{O}^{+}$ions. If the proton affinity of the VOCs is higher than that one of water, the VOCs are ionized. The $\mathrm{H}_{3} \mathrm{O}^{+}$ion performs a non-dissociative proton transfer to a majority of the VOCs. The mole fractions of a target compound were determined from the signal intensity at a specific mass to charge ratio $(\mathrm{m} / \mathrm{z})$. Fragmentation or charge transfer from $\mathrm{O}_{2}{ }^{+}$ion was not taken into account. After the drift tube, the ions are guided to a quadrupole mass spectrometer for the selection and detection of the ions. The instrument measures with one Thomson (Th) resolution, thus different compounds with same nominal $\mathrm{m} / \mathrm{z}$ cannot be distinguished.

The instrument of SMR II was calibrated using a VOC calibration standard (Apel-Riemer Environment Inc., Table 4) and VOC free air generated from ambient air with a catalytic converter. The calibration standard was diluted to a mole fraction of a few tens of nmol/mol. The instrumental background of the PTR-MS was determined by measuring VOC free air, and the background signals were subtracted from the measured signals. In the WCC-VOC the PTR-MS was calibrated using three dry gas standards in the low nmol/mol range (D64 1904: 28 hydrocarbon species with amount fractions of about $1 \mathrm{nmol} / \mathrm{mol}$; D64 1977: 17 component monoterpene mixture with benzene, toluene and isoprene, amount fractions about $2 \mathrm{nmol} / \mathrm{mol}$; D838784R: 29 NMHC mixture, amount fractions about $4 \mathrm{nmol} / \mathrm{mol}$; balance gas: nitrogen; National Physical Laboratory (NPL), UK, Central Calibration Laboratory for Non-Methane Hydrocarbons of WMO-GAW).

\section{$\underline{\text { Results and discussion }}$}

SMEAR II (SMR II), Hyytiälä (Finland), and WCC-VOC, Garmisch-Partenkirchen (Germany) (Figure 1, main paper), reported mole fractions for $\mathrm{m} / \mathrm{z} 69$ (parent ion for isoprene), $\mathrm{m} / \mathrm{z} 79$ (parent ion for benzene), and m/z 93 (parent ion for toluene and p-cymene) (Figure S1). For the NMHC_N $\mathrm{N}_{2} \mathrm{~m} / \mathrm{z}$ 69, WCC-VOC reported an amount fraction well within the ACTRIS data quality objective for 
observed. SMEAR II did not report isoprene. For $\mathrm{m} / \mathrm{z} 93$ and m/z 79 the results for both mixtures and for both stations were outside ACTRIS and GAW DQOs for toluene and benzene, respectively.

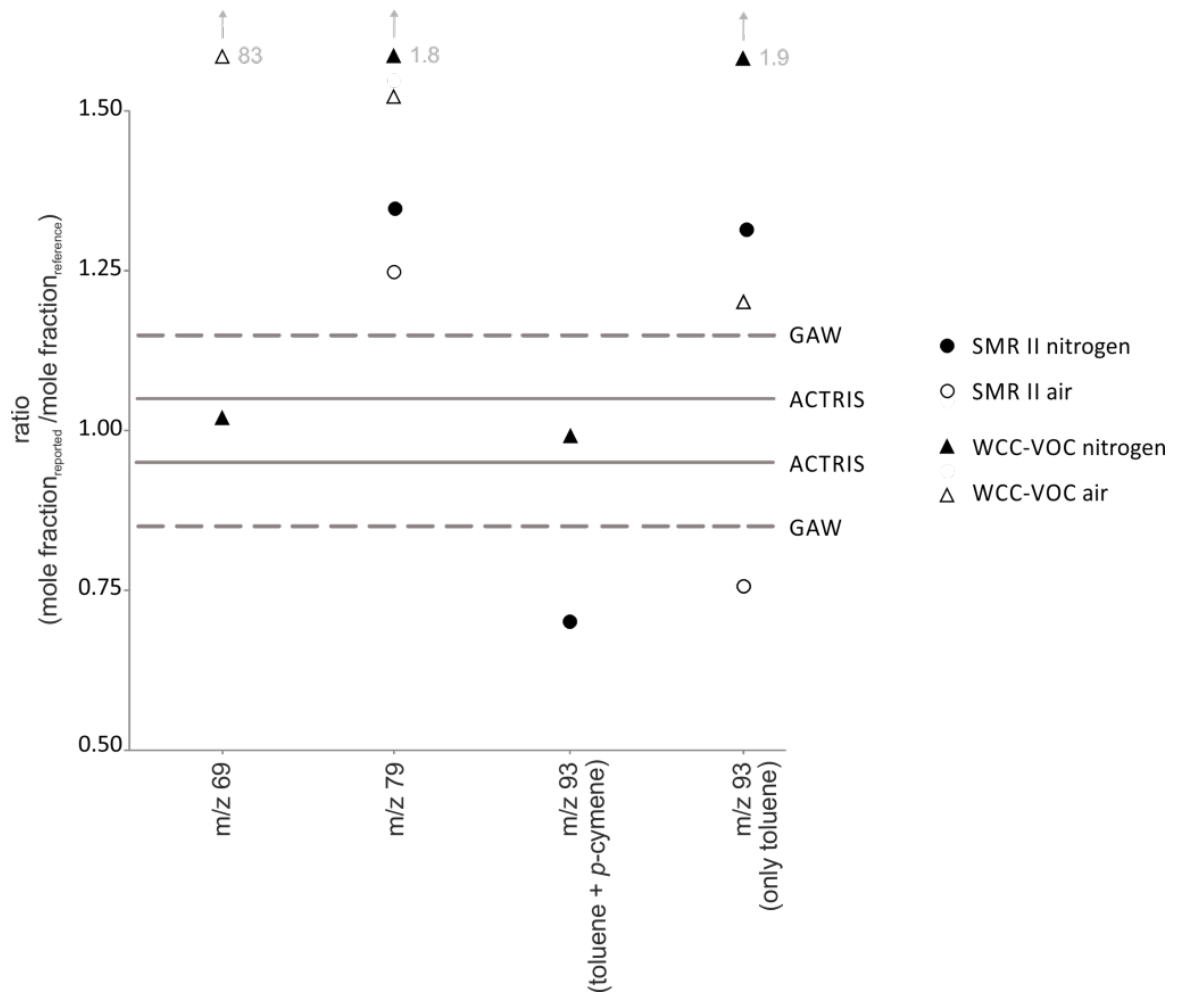

Figure S1: PTR-MS results for $\mathrm{m} / \mathrm{z} 69$ (isoprene), $\mathrm{m} / \mathrm{z} 79$ (benzene), $\mathrm{m} / \mathrm{z} 93$ (toluene $+p$-cymene) and toluene from SMR II and WCC-VOC are presented relative to the reference values. Closed and open circles/triangles indicate results in NMHC_ $\mathrm{N}_{2}$ and NMHC_air, respectively. Solid and dashed grey lines indicate ACTRIS and GAW data quality objectives, respectively (Table 2, main paper).

The differences to the assigned values in two NMHC mixtures (NMHC_N $\mathrm{N}_{2}$ and NMHC_air) may be attributed to the lack of compound specificity of the PTR-MS analytical system (Blake et al., 2009). It is well known in mass spectroscopy that a detected $\mathrm{m} / \mathrm{z}$ may be a result of different ions (parent ions, clusters, fragments). In the $\mathrm{NMHC}_{-} \mathrm{N}_{2}$ sample $\mathrm{m} / \mathrm{z} 69$ seem to represent isoprene as assigned and measured values are very close as shown by WCC-VOC. In NMHC_air, however, m/z 69 is most likely a mixture of different ions.

An ion screening of the NMHC_air by PTR-MS analysis spanning a m/z range from 21 to 161 performed by WCC-VOC revealed a huge amount of oxygenated VOC present in the gas cylinder. Compared to back ground air, amount fraction $\mathrm{m} / \mathrm{z} 59$ (e.g. parent ion for acetone or propanal) was doubled, $\mathrm{m} / \mathrm{z} 33$ (parent ion for methanol) was higher by a factor of $4.5, \mathrm{~m} / \mathrm{z} 45$ (e.g. parent ion for acetaldehyde) was increased by a factor of about 10. Amount fractions of other oxygenated VOC with $\mathrm{m} / \mathrm{z} 43$ (e.g. parent ion for propanol) and m/z 61 (e.g. parent ion for acetic acid) were 60 times and 200 times higher, respectively, as in background air. It is very likely that also for $\mathrm{m} / \mathrm{z} 69$ other compounds (e.g. pentanal) as isoprene were co-detected and thus the reported value was the amount fraction of 
alcohols or aldehydes rather than isoprene. In further GC-MS studies the exact composition of oxygenated VOC present in the ACTRIS air standards should be elucidated.

104 For $\mathrm{m} / \mathrm{z} 79$ (benzene) the difference to the assigned values may also be explained by co-detection of compounds. For $\mathrm{m} / \mathrm{z} 93$ (toluene $+p$-cymene) WCC-VOC obviously overestimated the toluene target values. As $p$-cymene was present in both gas cylinders this was expected. For NMHC_N $\mathrm{N}_{2}$ the $p$ cymene value was known $(1.07 \pm 0.079 \mathrm{nmol} / \mathrm{mol})$. As in $\mathrm{m} / \mathrm{z} 93$ both toluene and $p$-cymene were

108

109 detected, the target mole fraction in NMHC_ $\mathrm{N}_{2}$ for $\mathrm{m} / \mathrm{z} 93$ was therefore $2.29 \mathrm{nmol} / \mathrm{mol}$. This target mole fraction of $\mathrm{m} / \mathrm{z} 93$ was almost perfectly matched by WCC-VOC with a measured value of 2.27 $\mathrm{nmol} / \mathrm{mol}$. This highlights the weakness of the PTR-MS method; it does not detect changes in the chemical composition of the gas sample. Thus the PTR-MS was a method for monitoring changes in the concentrations of a known matrix, but not for the identification of the compounds. The reported value for $\mathrm{m} / \mathrm{z} 93$ from SMR-II when referenced to the sum of toluene and $p$-cymene in NHMC_ $\mathrm{N}_{2}$ underestimated the target by about $30 \%$. The same bias is observed when comparing the SMR-II data for other $\mathrm{m} / \mathrm{z}$ and other samples to values reported by WCC-VOC. These results may likely be traced back to uncertainties in the calibration process and changes in the gas sample composition.

When applying calibration factors for specific compounds gained for dry gas samples to ambient measurement conditions it has to be considered that humidity in the gas sample may influence the instrument response. As some water gets from the ion source to the reaction chamber, as well as from the sample air, water clusters $\mathrm{H}_{3} \mathrm{O}^{+}\left(\mathrm{H}_{2} \mathrm{O}\right)$ are always present in the reaction chamber. The drift tube ion chemistry includes ionization of the measured compounds as well as formation of water clusters, which are ionized, too. Since there is also some back drift of sample air into the ion source, the abundance of primary ions is also influenced by the air sample, e.g. amount of water vapor (Tani et al., 2003) and oxygen (Ennis et al., 2005). Many compounds have high enough water affinity to be protonated in the collision with the water cluster as well as with protonated water. Additionally, changes in relative humidity do affect the measured signals. However benzene and toluene do not react with water cluster and thus their signals are humidity dependent. The highest signals for benzene and toluene have been measured when the relative humidity was low (20\%) and the signals were decreasing with decreasing relative humidity (Warneke et al., 2001).

To conclude: while PTR-MS is a real-time, on-line method that is less labor intense than the GC-MS methods for monitoring changes in mole fractions, another method is needed for determining the chemical composition of the gas samples. For correctly assigning amount fractions with PTR-MS analysis to specific compounds, the composition of the gas matrix needs to be considered as well as cluster formation and compound fragmentation. In addition, standards used for calibration should be traceable to a common scale and if diluted standards are used, the error in the dilution ratio must be as small as possible to minimize the bias to target amount fractions. 


\section{$\underline{\text { References }}$}

139 Blake, R. S., Monks, P. S., and Ellis, A. M.: Proton-Transfer Reaction Mass Spectrometry, Chem. Rev., 109, 861-896, 2009.

De Gouw, J. and Warneke, C.: Measurements of volatile organic compounds in the earth's atmosphere using proton-transfer-reaction mass spectrometry, Mass Spectrom Rev, 26, 223-257, 2007.

De Gouw, J., Warneke, C., Karl, T., Eerdekens, G., Van der Veen, C., and Fall, R.: Sensitivity and specificity of atmospheric trace gas detection by proton-transfer-reaction mass spectrometry, Int. J. Mass Spectrom., 223-224, 365-382, 2003a.

de Gouw, J. A., Goldan, P. D., Warneke, C., Kuster, W. C., Roberts, J. M., Marchewka, M., Bertman, S. B., Pszenny, A. A. P., and Keene, W. C.: Validation of proton transfer reaction-mass spectrometry (PTR-MS) measurements of gas-phase organic compounds in the atmosphere during the New England Air Quality Study (NEAQS) in 2002, Journal of Geophysical Research D: Atmospheres, 108, ACH 10-11 - ACH 10-18, 2003b.

Ennis, C. J., Reynolds, J. C., Keely, B. J., and Carpenter, L. J.: A hollow cathode proton transfer reaction time of flight mass spectrometer, Int. J. Mass Spectrom., 247, 72-80, 2005.

Lindinger, W., Hansel, A., and Jordan, A.: On-line monitoring of volatile organic compounds at pptv levels by means of Proton-Transfer-Reaction Mass Spectrometry (PTR-MS) Medical applications, food control and environmental research, Int. J. Mass Spectrom. Ion Proces., 173, 191-241, 1998.

Taipale, R., Ruuskanen, T. M., Rinne, J., Kajos, M. K., Hakola, H., Pohja, T., and Kulmala, M.: Technical note: Quantitative long-term measurements of VOC concentrations by PTR-MS Measurement, calibration, and volume mixing ratio calculation methods, Atmospheric Chemistry and Physics, 8, 6681-6698, 2008.

Tani, A., Hayward, S., and Hewitt, C. N.: Measurement of monoterpenes and related compounds by proton transfer reaction-mass spectrometry (PTR-MS), Int. J. Mass Spectrom., 223-224, 561-578, 2003.

Warneke, C., De Gouw, J. A., Kuster, W. C., Goldan, P. D., and Fall, R.: Validation of atmospheric VOC measurements by proton-transfer-reaction mass spectrometry using a gas-chromatographic preseparation method, Environmental Science and Technology, 37, 2494-2501, 2003.

Warneke, C., Van Der Veen, C., Luxembourg, S., De Gouw, J. A., and Kok, A.: Measurements of benzene and toluene in ambient air using proton-transfer-reaction mass spectrometry: Calibration, humidity dependence, and field intercomparison, Int. J. Mass Spectrom., 207, 167-182, 2001. 